\title{
DESENVOLVIMENTO DE KITS DIDÁTICOS E CURSOS DE ROBÓTICA EDUCACIONAL: UM ESTUDO DA METODOLOGIA QUE PODE SER EMPREGADA EM PROJETOS DE EXTENSÃO
}

\author{
DIDACTIC KITS DEVELOPMENT AND EDUCATIONAL ROBOTICS \\ COURSES: A STUDY OF METHODOLOGIES WHICH MAY BE USED IN \\ EXTENSION PROJECTS
}

\author{
Luis Fernando \\ Freire Souza ${ }^{1}$; Gabriela Lígia Reis ${ }^{2}$; Mateus Porreca Tavares ${ }^{3}$; Cássio Nascimento Lopes ${ }^{4}$; \\ Eduardo Bento Pereira ${ }^{5}$ : Márcio Falcão Santos Barroso ${ }^{6}$
}

\begin{abstract}
RESUMO
A robótica tem se mostrado uma excelente ferramenta de apoio ao ensino fundamental e médio. A aplicação dos conceitos estudados em sala de aula, a motivação dos alunos, a busca por novos conhecimentos, o trabalho em equipe e o desenvolvimento do raciocínio lógico são alguns dos benefícios proporcionados por trabalhos nesta área. Entretanto, a robótica educacional ainda não consegue atingir grande parte dos estudantes, sobretudo na rede pública de ensino. Isso se deve a dois fatores principais: o custo elevado dos kits e materiais necessários para a realização das aulas e a falta de capacitação dos professores. Neste sentido, este artigo apresenta os projetos que vêm sendo desenvolvidos pelo Núcleo de Cibernética e Sistemas Robóticos (CyRoS) da Universidade Federal de São João del-Rei (UFSJ) voltados para a robótica educacionalno ensino fundamental, médio e na educação especial. Estes trabalhos têm como foco o desenvolvimento de kits didáticos de baixo custo, a realização de cursos para os professores e a elaboração de materiais didáticos, como apostilas e vídeo aulas que possam ser utilizados como base para a ampliação e a continuação dos projetos no ambiente escolar.
\end{abstract}

Palavras-chave: Robótica Educacional,Kits de baixo Custo, Capacitação de Professores, Inclusão Social.

\begin{abstract}
Robotics has become an excellent tool to support middle and high school. The application of the concepts studied in class, student motivation, the search for new knowledge, teamwork and the development of logical reasoning are some of the benefits provided by work in this area. However, educational robotics still can't reach most students, especially in public schools. This is due to two main factors: the high cost of kits and materials needed to conduct the classes and the lack of qualified teachersThus, this article presents the educational robotics projects that have been developed by the Center for Robotic Systems and Cybernetics (Cyros) Federal University of São João del-Rei (UFSJ) for education in primary, secondary and special education. These studies have focused on the development of low-cost educational kits, conducting courses for teachers and development of teaching materials such as hand outs and video lessons that can be used as a basis for the expansion and continuation of projects in the school environment.
\end{abstract}

Keywords: Educational Robotics. Low Cost Kits. Empowerment of teachers. Social Inclusion.

\footnotetext{
${ }^{1}$ Universidade Federal de São João del-Rei. Email: Inandoffs@hotmail.com

2 Universidade Federal de São João del-Rei. Email: gabireis@yahoo.com.br

${ }^{3}$ Universidade Federal de São João del-Rei. Email: mporrecat@hotmail.com

${ }^{4}$ Universidade Federal de São João del-Rei. Email: kcio-lopes@hotmail.com

${ }^{5}$ Universidade Federal de São João del-Rei. Email: ebento@ufsj.edu.br

${ }^{6}$ Universidade Federal de São João del-Rei. Email: $\underline{\text { barroso@ufsj.edu.br }}$
} 


\section{INTRODUÇÃO}

No contexto de sala de aula, o processo de aprendizagem do aluno está ligado a diversos fatores, dentre eles, Silva (2005) destaca o papel do professor e a qualidade do ambiente escolar. Desta forma, é importante que o aluno encontre na escola ferramentas por meio das quais ele possa aplicar o conhecimento adquirido, bem como profissionais capacitados que possam auxiliá-lo nesta tarefa.

Neste cenário, a robótica tem apresentando um grande potencial como ferramenta multidisciplinar, promovendo a aprendizagem de forma lúdica e prazerosa. A Física e a Matemática, por exemplo, que são tomadas como disciplinas difíceis de aprender, por conterem conceitos abstratos (GOMES et. al., 2008), podem se tornar muito mais interessantes quando o aluno percebe a necessidade de utilizá-las na prática. Além disso, não só os conhecimentos específicos são aprimorados, a busca pela resolução de problemas leva o aluno a fazer questionamentos e debater soluções, estimulando o raciocínio lógico, o trabalho em equipe e a criatividade.

Outro ponto importante da robótica educacional é a inclusão digital. "Vivemos em uma nova era tecnológica. Neste novo ambiente social, comunicação e informação tornaramse uma necessidade." (THOMAZ et. al., 2009, p.1).

Promover a inclusão digital é algo que, além das questões sociais envolvidas é um direito que o cidadão tem de participar das tecnologias existentes, de ter uma educação mais atualizada, capacitação profissional e maior competitividade no mercado. (COSTA et. al., 2007, p. 2).

Entretanto, apesar de todos os benefícios que a robótica educacional pode trazer para os alunos do ensino fundamental e médio, "é recente, no Brasil, pensar as possibilidades do robô no campo escolar e educacional" (FRANCISCO JÚNIOR et. al., 2010: 3) e na maioria dos casos são realizadas pelas universidades. É o caso dos projetos descritos em (VALLIM et. $a l, 2009)$ e (ANGONESE et. al., 2012). Esses projetos são muito interessantes, pois não só os alunos das escolas são beneficiados, mas os alunos de graduação também, sobretudo pela possibilidade de aprender com o ato de ensinar, como mostram REIS et. al. (2011). Contudo, muitas vezes esses trabalhos não conseguem atingir todos os alunos ou não têm continuidade.

Um dos problemas que impedem o avanço da robótica educacional está relacionado ao custo do material necessário para a realização das aulas, que ainda é proibitivo. 
No desenvolvimento de uma aula de robótica educacional são utilizados kits de robótica, compostos por componentes mecânicos estruturais e de movimento, motores, sensores e um controlador programável. Além disso, é necessário o uso de um hardware associado a uma linguagem de programação, capaz de programar o kit de robótica, um computador capaz de utilizar o software escolhido, e um ambiente físico no qual devem existir elementos capazes de interagir com o robô na realização de uma determinada atividade. (FERNANDES, et. al., 2012, p.1).

Neste sentido, diversos trabalhos como (RAMOS, et. al. 2007) e (AROCA, 2012) estão mostrando formas alternativas e mais acessíveis de utilizar os robôs no ambiente escolar. Estes projetos apontam para o uso de materiais recicláveis, e de plataformas de hardware de código aberto, como o Arduino. Considerando-se essas alternativas, o avanço da robótica educacional depende ainda do treinamento e capacitação dos professores para que os mesmos possam continuar o trabalho realizado dentro das escolas, relacionando os conteúdos vistos em sala de aula com as atividades práticas.

Tendo em vista todas estas questões, este trabalho apresenta os projetos de robótica educacional que vêm sendo desenvolvidos pelo Núcleo de Cibernética e Sistemas Robóticos (CyRoS), uma iniciativa de professores e alunos da Universidade Federal de São João del-Rei (UFSJ) que tem por objetivo o ensino, pesquisa e extensão relacionados à robótica e áreas afins. No âmbito da extensão, o foco do grupo está voltado para o trabalho com materiais de baixo custo e alternativos, bem como para a capacitação de professores do ensino fundamental e médio e da educação especial, incluindo assim no programa alunos com deficiência.

\section{DESENVOLVIMENTO}

O Núcleo de Cibernética e Sistemas Robóticos (CyRoS) é um grupo de trabalho ligado ao Departamento de Engenharia Elétrica (DEPEL) da Universidade Federal de São João delRei (UFSJ). O Núcleo possui diversos trabalhos de Pesquisa, Ensino e Extensão nas áreas de robótica, tecnologias assistivas e sistemas inteligentes. Estes trabalhos são agrupados em cinco grandes projetos: UAIrobots, UaiSoccer, UAIrobots Junior, UAIrobots EKO e UAIrobots Assistant. O grupo conta com sete professores e mais de cem alunos dos cursos de Engenharia Elétrica, Mecânica, Produção, Mecatrônica, Ciência da Computação, Arquitetura, Matemática, Física, Química, Psicologia e Pedagogia. Além dos projetos citados, o Núcleo organiza eventos em robótica como a Olimpíada e Mostra de Robótica do Campo das 
Vertentes (ORCV e MRCV, respectivamente), a Copa Mineira de Simulação 2D e o Workshop de Acessibilidade, Robótica e Tecnologia Assistiva (WARTA).

Dentre os projetos apresentados, o UAIrobots foi criado por iniciativas de professores e alunos da UFSJ. UAI se refere a duas referências: Unidades Autônomas Integradas, ideia original do projeto e, também a expressão mineira tão conhecida nacionalmente. O Projeto ainda em discussão consiste em atividades integradas e voluntárias que focam desde o uso da robótica em escolas de ensino fundamental e médio até a pesquisa em nível de pós-graduação.

Com o foco direcionado para a extensão, pode-se destacar entre esses projetos, o UAIrobots Júnior, em que seu objetivo consiste em levar a robótica educacional às escolas como instrumento motivacional e didático, permitindo assim aos alunos e professores o contato com este tipo de tecnologia.

Neste contexto, integrado aos trabalhos de extensão desse grupo e com grande apelo social, destaca-se também o projeto nomeado UAIrobots EKO. Esse projeto tem como principal intuito a construção de kits didáticos de baixo custo com materiais reciclados e eletrônicos.

Portanto, a intenção da criação desses kits é de proporcionar um destino apropriado aos materiais reciclados, tendo como contrapartida a utilização desses materiais nos kits didáticos direcionados para o ensino de alunos de escolas públicas. Desta forma, esses kits são construídos com os materiais chamados de "lixo eletrônico", ou seja, o lixo proveniente de equipamentos eletroeletrônicos.

Assim, com a utilização desse material é possível evitar gastos, pois parte dos componentes presentes nos kits educacionais desenvolvidos nesse projeto são retirados do lixo tecnológico, evitando dessa forma a sua compra. Por outro lado, em contrapartida, esse lixo eletrônico é doado pela população ou por empresas que queiram formar parcerias com esse projeto.

\section{RESULTADOS}

Os resultados desse trabalho se concentram na metodologia empregada, nos kits e robôs desenvolvidos e no público atingido. Assim, esses resultados são integrados por três cursos, sendo esses envolvendo a Linguagem Logo, Robótica Educacional e Capacitação de Professores. A seguir serão detalhados todos esses subprojetos citados. 


\section{Linguagem Logo}

Esse trabalho envolve o projeto nomeado "Incentivo à aprendizagem da matemática e robótica básica por meio da linguagem de programação Logo”. O projeto utiliza um software gratuito que tem por objetivo o ensino da robótica, matemática e programação para crianças. O software Logo em questão é uma linguagem computacional que foi desenvolvida em 1967 por um grupo de pesquisadores do Massachusetts Institute of Tchnology (MIT), em Boston, nos Estados Unidos, sob a direção de Seymour Papert, professor de Matemática desta mesma instituição.

Sua proposta consiste em colocar a criança para comandar um robô ou sua representação na tela do computador. Um dos primeiros robôs controlados por essa linguagem lembrava a forma de uma tartaruga, desde então a tartaruga passou a ser o seu símbolo. Por meio dela, o computador passa a ser usado como uma ferramenta para a criança realizar ações como comandar o robô ou fazer desenhos, incentivando dessa maneira sua imaginação e criatividade (PIMENTEL, 2012).

O software trabalhado nas escolas é o KTurtle, um ambiente educativo de programação e sem fins lucrativos. Este software foi desenvolvido para o sistema operacional Linux $^{\circledR}$ e utiliza o TurtleScript, uma linguagem de programação vagamente baseada e inspirada pelo Logo. O objetivo do KTurtle é proporcionar um ambiente de programação acessível e de fácil entendimento para os usuários. Desta maneira, se torna uma importante ferramenta para o ensino da matemática, geometria, língua portuguesa e programação (BREIJS, 2012). A Figura 1 exibe a interface desse software, ilustrando uma atividade prática executada pelos alunos nas aulas, na qual o objetivo era atribuir os comandos necessários para deslocar o robô virtual, do centro do labirinto e colocá-lo dentro do retângulo. 


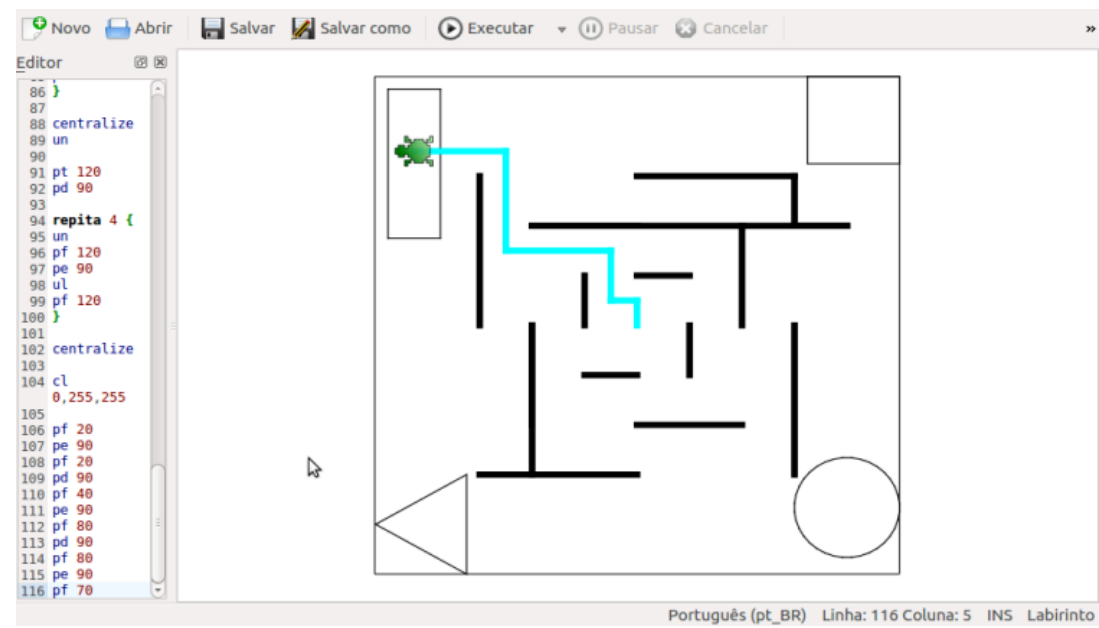

Figura 1 - Atividade do labirinto proposta na aula.

Para executar esta tarefa os alunos primeiramente tiveram que identificar qual das quatro figuras geométricas mostradas na tela do computador da Figura 1 é o retângulo. Por fim, as crianças tiveram que fornecer os comandos necessários para deslocar o robô e cumprir a tarefa.

Esse projeto tem como público alvo alunos do ensino fundamental, sendo a faixa etária desses estudantes de 6 a 9 anos, classificados nas turmas de nível 0. As aulas desse curso têm duração de uma hora e são realizadas duas vezes por semana, sendo as essas oferecidas no turno do ensino fundamental nas próprias escolas. Atualmente, participam desse trabalho quatro escolas da cidade de São João Del Rei, sendo esse projeto realizado em pelo menos uma turma de cada escola, selecionando turmas do primeiro ano até o quarto ano do ensino fundamental. Cada turma é formada com no máximo vinte e cinco alunos, sendo esses com variados graus de desempenho escolar. No total participam desse projeto em torno de cem alunos. Já para as aulas, cada turma conta com um instrutor em linguagem Logo e quatro monitores.

Uma das ideias futuras desse projeto está na utilização do robô Turtle (Tartaruga) construído com materiais reciclados, como CDs, tampinhas e garrafa PET, como ilustrado na Figura 2. Esse robô utilizará o microprocessador arduino que comunicará via bluetooh com um circuito que coleta as informações da porta paralela do computador emitidas pelo software KTurtle ou SuperLogo, sendo este na versão Windows. Assim, possibilitará que o aluno forneça os comandos ao robô virtual e ao robô Turtle. 


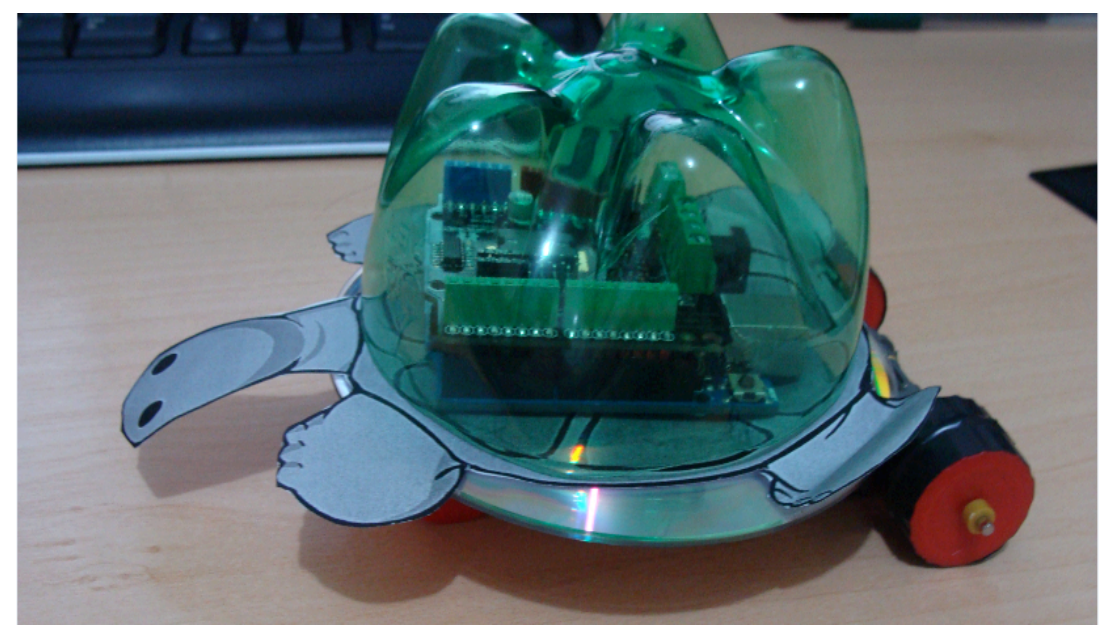

Figura 2- Robô Turtle.

\section{Robótica Educacional}

Esse trabalho engloba dois programas nomeados "A robótica e a inclusão social: tecnologia e acessibilidade aplicadas ao ensino" e "A multidisciplinaridade da robótica aplicada ao desenvolvimento de crianças e adolescentes e a realização da IV ORCV Olimpíada de Robótica do Campo das Vertentes 2013”. Neste sentido, esse curso é composto por ciclos ou módulos que vão do básico ao avançado na área de robótica educacional. Cada ciclo pode ser cursado no período de dois, quatro ou seis meses. Inicialmente, os projetos são realizados na Tecnoteca da UFSJ, que consiste num laboratório que contém arenas de treinamento, computadores, bancadas, datashow e kits didáticos de robótica. A intenção desse trabalho é de estreitar as parcerias com as escolas situadas no Campo das Vertentes, de modo que cada uma possa contar com sua própria Tecnoteca.

Esse projeto tem como público alvo alunos do ensino fundamental, médio e educação especial, incluindo assim estudantes com deficiência, sendo a faixa etária desses alunos de dez a dezenove anos. Os alunos de dez a quatorze anos são classificados nas turmas de nível $1 \mathrm{e}$ de quinze a dezenove anos nas turmas de nível 2. O curso é o mesmo para alunos do nível 1 e 2 diferindo apenas no aprofundamento dos temas de ciências e exatas tratados nas aulas.

As aulas têm duração de duas horas e são realizadas duas vezes por semana, sendo oferecidas no contra turno do ensino fundamental e médio.Atualmente, participam desse trabalho oito escolas da cidade de São João del-Rei. De cada escola participam oito alunos com variados graus de desempenho escolar, sendo quatro que estão cursando o ensino fundamental e quatro do ensino médio. No total participam desse projeto sessenta e quatro alunos, sendo estes divididos em quatro turmas compostas por dezesseis alunos. Cada turma 
conta com um instrutor em robótica educacional e quatro monitores. Neste curso, a determinação da quantidade de turmas atendidas foi definida diante da limitação de kits didáticos disponíveis. Porém, a intenção desse trabalho é de se estender a mais alunos e escolas da rede de ensino do Campo das Vertentes e outras localidades.

Dentre os resultados obtidos nesse trabalho pode-se destacar a elaboração do kit de baixo custo de eletrônica básica montado para as aulas do curso de robótica educacional. A seguir o Quadro 1 exibe o preço correspondente de cada componente presente no kit.

Quadro 1 - Componentes e preços do kit de eletrônica básica.

\begin{tabular}{|c|c|c|}
\hline Quantidade & Componentes & Preços (R\$) \\
\hline 1 & Microprocessador Arduino UNO & 69,00 \\
\hline 1 & Arduino motor shield 2A & 68,00 \\
\hline 2 & Rodas Tamiya & 19,00 \\
\hline 1 & Motor de corrente continua & Reciclado \\
\hline 1 & Resistor Dependente de Luz (LDR) 5" & 0,45 \\
\hline 1 & Miniprotobord & 2,40 \\
\hline 1 & Sensor de temperatura Lm35 & 4,50 \\
\hline 8 & Diodo Emissor de Luz (LED) & Reciclado \\
\hline 4 & Botão de dois terminais & Reciclado \\
\hline 1 & Sinalizador elétrico Buzzer & Reciclado \\
\hline 1 & LED RGB & 2,40 \\
\hline 1 & Conector empalhável 4 pinos & 8,00 \\
\hline 1 & Conector empalhável 2 pinos & 5,00 \\
\hline 4 & Resistores & 0,40 \\
\hline 1 & Interruptor magnético Reed switch & 2,00 \\
\hline 4 & Bornes (Conectores) & 1,50 \\
\hline 1 & Caixa organizadora com 16 divisões & 10,40 \\
\hline 4 & Pilhas recarregáveis & 19,50 \\
\hline & CUSTO TOTAL & $\mathbf{2 1 2 , 5 5}$ \\
\hline
\end{tabular}

De acordo, com o Quadro 1 é possível perceber que o valor total para a montagem desse kit de eletrônica básica foi de R \$212,55, ou seja, um valor relativamente barato quando comparado a kits prontos. Outro ponto positivo é a facilidade da utilização desse kit, possibilitando ser usado em diversas montagens e experimentos.

A Figura 3 ilustra o kit mencionado. Já o kit didático com peças mecânicas para a construção dos robôs, será utilizado o kit da Modelix ${ }^{\circledR}$ e o material reciclado como garrafa PET, papelão, CDs e entre outros. 


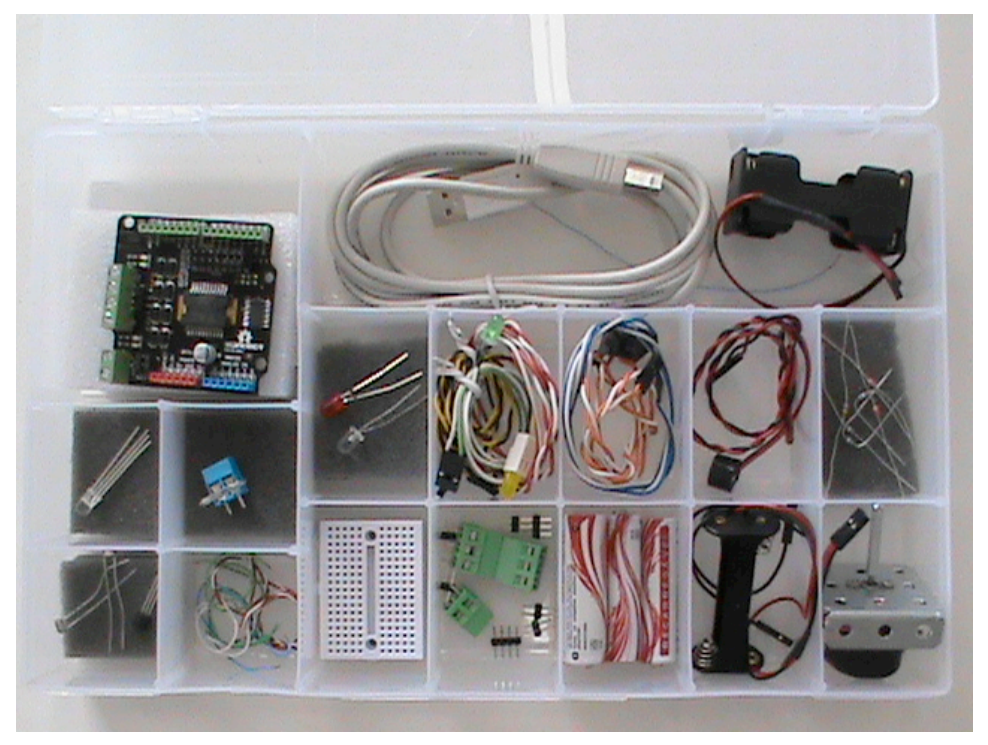

Figura 3 - Kit de eletrônica básica.

Além disso, outro ponto interessante da metodologia empregada nesse trabalho está na criação de vídeo aulas e no desenvolvimento de apostilas. Pensando no vídeo como uma forma de complementar a educação tradicional, e não simplesmente substituí-la. Para isso, é necessário que se identifique as necessidades dos alunos alvo e se produza vídeos específicos com esse conteúdo. Vídeos que trabalhem as dificuldades dos alunos e que sejam mais objetivos têm maiores chances de obter sucesso. Com uma extensão dessa característica, o uso de vídeos curtos também tem melhores resultados, por isso, este tipo de vídeo será adotado na implementação desse trabalho. O intuito da criação dessas vídeo-aulas é estimular os alunos a pesquisarem por vontade própria os temas trabalhados nas aulas práticas, uma vez que as mesmas terão o foco na parte lúdica e experimental, enquanto as vídeo aulas tratarão dos temas abordados de uma maneira mais teórica. Além disso, esse material ainda poderá ser utilizado posteriormente pelos professores e alunos das escolas, proporcionando a ampliação e a continuação do projeto.

\section{Capacitação de Professores}

Esse trabalho envolve o projeto nomeado "Capacitação de professores do ensino fundamental e médio no uso da robótica educacional e de Tecnotecas como elementos motivadores da aprendizagem”. Dessa forma, consiste em uma ação ampla para a difusão do 
uso da robótica educacional como ferramenta motivadora da aprendizagem por meio da capacitação de professores do ensino fundamental e médio.

Esta capacitação dos professores pode ser dividida em três ferramentas básicas: linguagem de programação Logo, programação de microprocessador tipo arduino e uso de kits didáticos em robótica educacional. A capacitação utilizando a linguagem Logo foi organizada em uma escola da cidade de São João del-Rei, participando desse treinamento professores atuantes em turmas do ensino fundamental. Já a capacitação em microprocessador tipo arduino e uso de kits didáticos em robótica educacional estão sendo desenvolvidos na Tecnoteca da UFSJ, incluindo nesta turma além de professores do ensino fundamental e médio, também os que atuam no presídio.

Para a capacitação dos professores, neste projeto também foi desenvolvido o robô seguidor de linha que utiliza a sua estrutura construída de acrílico, como ilustra a Figura 4.Esse robô foi projetado tendo dois sensores infravermelhos situados na parte inferior central para atuar como percepção da linha. Já para executar o controle dos motores foram utilizados o microprocessador arduino UNO e o shield de motor. Um ponto interessante desse robô está associado na facilidade de conexões de sensores ou montagem de circuitos eletrônicos, uma vez que na região superior do mesmo possui um miniprotobord. Assim, esse robô também foi utilizado pelos alunos do ensino fundamental e médio na Olímpiada de Robótica do Campo das Vertentes de 2012.

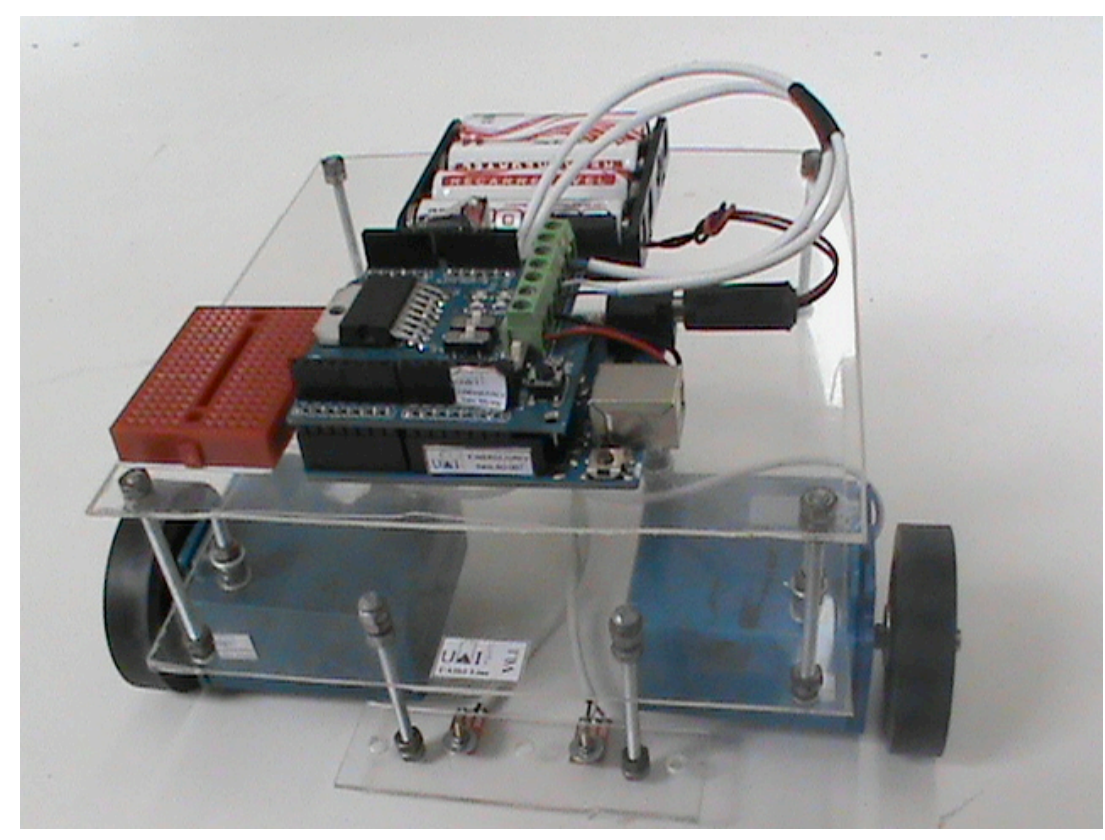

Figura 4 - Robô ORCV 2012. 
Diante do primeiro modelo apresentado na Figura 4, neste projeto também foi desenvolvido outro robô seguidor de linha que utiliza a sua estrutura construída de materiais descartados, como CDs, acrílico e garrafas PET. Assim, para a construção desse novo robô foram utilizados os mesmos sensores infravermelhos comentados acima, porém a sua estrutura foi modificada para conectarem aos novos motores de corrente contínua. A Figura 5 exibe o robô mencionado.

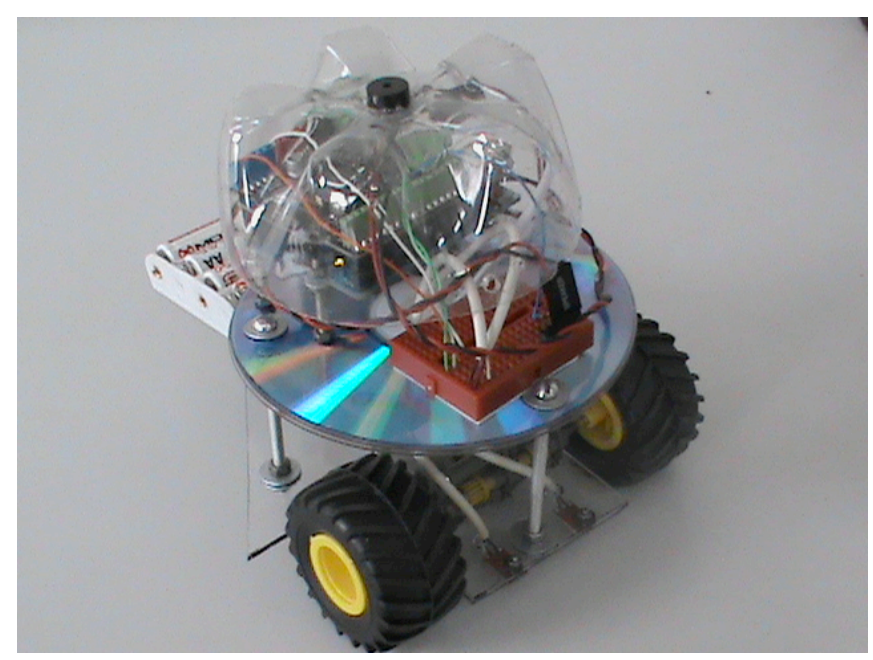

Figura 5 - Robô seguidor de linha.

Outro robô também construído com materiais reciclados e destinado para a extensão é o robô nomeado Lizard (lagarto), sendo este na versão esteira. Um ponto interessante que pode ser destacado nesse modelo é devido a sua estrutura ser construída de capa de caderno, como ilustra a Figura 6. 


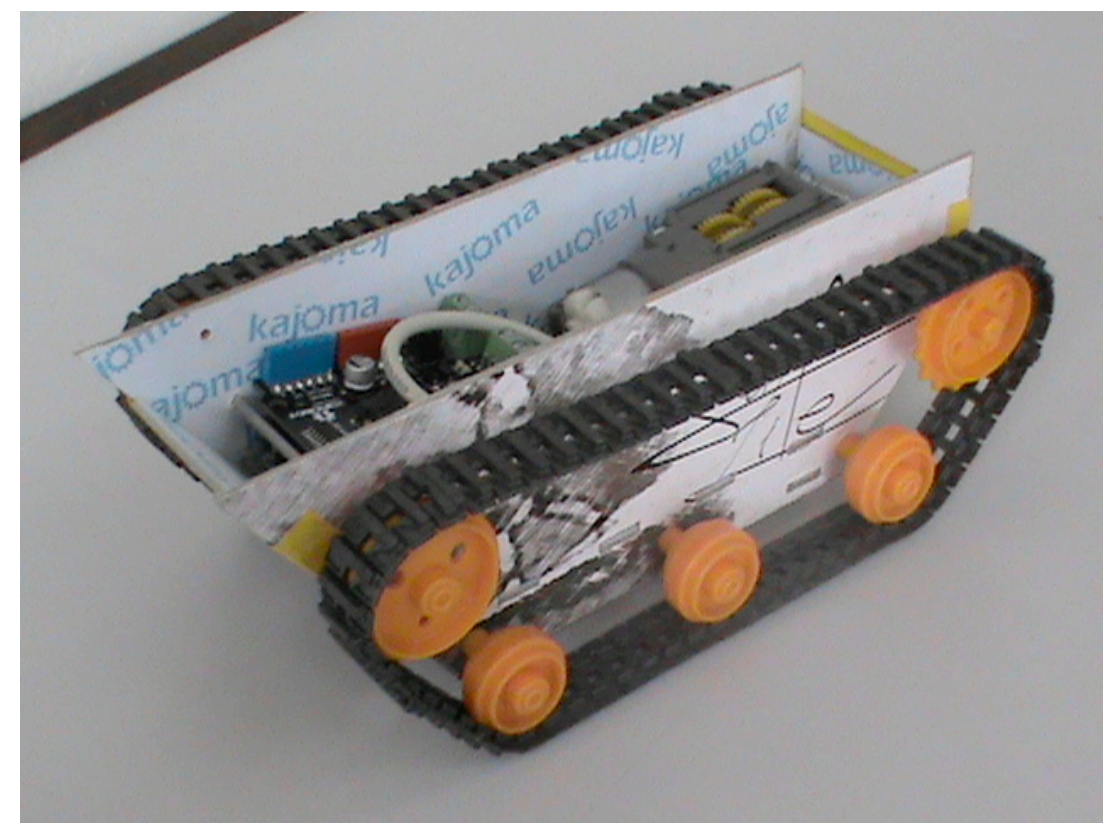

Figura 6 - Robô Lizard.

O intuito da construção desses robôs foi deles serem utilizados nas aulas do curso de robótica educacional tanto para os alunos quanto para a capacitação dos professores. Além disso, todos esses robôs mencionados também poderão ser utilizados pelos alunos participantes desse projeto nos eventos locais organizados pelo Núcleo de Cibernética e Sistemas Robóticos como a Mostra e Olimpíada de Robótica do Campo das Vertentes.

\section{CONCLUSÃO}

Este artigo apresentou quatro projetos voltados para a robótica educacional, cujo público alvo envolve professores e alunos com faixa etária de seis a dezenove anos do ensino fundamental, médio e da educação especial, proporcionando assim a inclusão de pessoas com deficiência.

.Entre os pontos de grande relevância discutidos nesse trabalho podem-se destacar a construção de kits de baixo custo. Esses kits têm um papel muito importante, pois, além de ser viável a sua implementação nas escolas, em detrimento de outros kits encontrados no mercado, cujo valor ainda é proibitivo, eles ainda permitem o reaproveitamento de materiais que seriam descartados na natureza e que passam a ser então reutilizados em prol do ensino. Isto também contribui para a formação social dos alunos, no que diz respeito ao meio ambiente e a cidadania.

Desta forma, é importante ressaltar a capacitação dos professores envolvidos neste projeto e a criação dos kits educacionais com o intuito de proporcionar futuramente a 
autonomia da criação nas escolas de Tecnotecas e profissionais capacitados em robótica educacional.

Outro aspecto importante é a nova abordagem desenvolvida na metodologia destes projetos, que visa estimular o aluno na busca pelo conhecimento. Espera-se que com a elaboração de apostilas e vídeo aulas os alunos se tornem mais proativos. Assim, o tempo reservado para as aulas de robótica é dedicado apenas às atividades lúdicas e experimentais e, uma vez despertado o interesse do aluno, o mesmo irá procurar meios de aprofundar o seu conhecimento, tendo como referência a apostila e as vídeo aulas elaboradas.

Para os alunos de graduação envolvidos no projeto foi uma experiência de grande aprendizado. O contato com diferentes softwares de programação e com a robótica foi uma forma de aprofundar os conhecimentos obtidos no curso e despertar o interesse dos alunos para áreas como controle e automação. O trabalho de extensão além de ser gratificante também é uma forma de aprender a lidar com questionamentos por parte dos alunos e situações inusitadas que tornam as aulas um desafio a cada dia.

Desta forma, os benefícios resultantes desse trabalho assumem dimensões consideráveis, tendo em vista o papel da universidade junto às dificuldades vivenciadas pelo ensino fundamental e médio nacional atual e a motivação dos estudantes pela área.

\section{AGRADECIMENTOS}

À Fundação de Amparo a Pesquisa do Estado de Minas Gerais (FAPEMIG), à PróReitoria de Extensão e Assuntos Comunitários (PROEX), ao Programa de Extensão Universitária (PROEXT), ao Instituto Nacional de Engenharia Elétrica (INERGE), ao CNPq, ao CAPES pelo apoio financeiro, à Universidade Federal de São João del-Rei (UFSJ) pelo apoio logístico e infraestrutura física. Por fim, também os agradecimentos a todas as escolas envolvidas pela participação e parceria, aos professores dessas escolas e alunos de graduação e professores da UFSJ pelo auxílio durante a execução desse projeto.

\section{REFERÊNCIAS}

ANGONESE, A. T.; ROSA, P. F. F.; RODRIGUES, S. H. Projeto de Integração EngenhariaEscola para Competições de Robótica. In: Workshop de Robótica Educacional, 1., 2012, Fortaleza. 
AROCA, R. V. Plataforma Robótica de Baixíssimo Custo para Robótica Educacional. 2012. 132 f. Tese (Doutorado em Ciências), Centro de Tecnologia, Universidade Federal do Rio Grande do Norte, Natal. 2012.

BREJIS, C.; MAHFOUF, A.; PIACENTINI, M. Manual do KTurte. Disponível em: $<$ http://docs.kde.org/stable/pt_BR/kdeedu/kturtle/index.html> Aceso em: 16 set. 2013.

COSTA, R. L.; THEREZA JUNIOR, A. H.; GOMIDE, R. S.; GOMIDE, R. V. S.; DAMASCENO, E. F. Informática Básica nas Escolas Públicas Buscando a Inclusão Digital dos Estudantes da Oitava Série do Ensino Fundamental em diante e da Comunidade em Geral. In: Congresso da Sociedade Brasileira de Computação, 27., 2007. Rio de Janeiro. Anais do XXVII Congresso da Sociedade Brasileira de Computação, Rio de Janeiro, 2007. p. 01-06.

FERNANDES, C. C.; SÁ, S. T.; GONÇALVES, L. M. G. Uma Nova Abordagem em Robótica Educacional Utilizando Simuladores e Kits de Robótica Livre. In: Workshop de Robótica Educacional, 1., 2012, Fortaleza.

FRANCISCO JÚNIOR, N. M.; VASQUES, C. K.; FRANCISCO, T. H. Robótica Educacional e a Produção Científica na Base de Dados da Capes. Revista Electrónica de Investigación y Docencia (REID), v. 4, Julho, 2010, 35-53. Disponível em: $<$ http://revistaselectronicas.ujaen.es/index.php/reid/article/view/1044>. Aceso em: 16 set. 2013.

GOMES, T.V.; MARTINS, S. A. M.; TEIXEIRA, W. W. M.; RICCO, R. A.; NEPOMUCENO, E. G. A Escolha da Engenharia como Curso Superior: Um Estudo de Caso com Alunos de Ensino Médio de uma Escola Pública. In: Congresso Brasileiro de Ensino de Engenharia, 36. São Paulo, 2008. Anais do XXXVI Congresso Brasileiro de Ensino de Engenharia, São Paulo, 2008. p. 01-08.

PIMENTEL, M. "Linguagem LOGO", Disponível em: $<$ http://sites.google.com/site/infoeducunirio/perspectiva-construtivista/linguagem-logo $>$. Acesso em 16 set. 2013. 
RAMOS, J. G.; NEVES JR, O. R.; D’ABREU, J. V. V. Iniciativa para Robótica Pedagógica Aberta e de Baixo Custo para Inclusão Social e Digital no Brasil. In: Simpósio Brasileiro de Automação Inteligente, 8., 2007, Florianópolis. Anais do VIII Simpósio Brasileiro de Automação Inteligente, Florianópolis, 2007. p. 01-06.

REIS, G. L.; SOUSA, M. V.; SOUZA, L. F. F.; ALMEIDA, V. M. O.; BARROSO, M. F. S.; NEPOMUCENO, E. G.; AMARAL, G. F. V. Integração entre ensino médio e engenharia por meio de atividades extensionistas na área de robótica e inclusão digital. In: Congresso Brasileiro de Ensino de Engenharia, 39., 2011, Blumenau. Anais do XXXIX Congresso Brasileiro de Ensino de Engenharia, Blumenau, 2011. p. 01-10.

SILVA, C. C. A Informática Educativa e as Dificuldades da Aprendizagem na Educação Infantil. 2005. 61f. Monografia (Pós-Graduação em Tecnologia Educacional) - Projeto a Vez do Mestre, Conjunto Universitário Candido Mendes, Rio de Janeiro. 2005.

THOMAZ, S.; AGLAÉ, A.; FERNANDES, C.; PITTA, R.; AZEVEDO, S.; BURLAMAQUI, A.; SIlvA, A.; GONÇALVES, L. M. G. RoboEduc: A Pedagogical Tool to Support Educational Robotics. 39 $9^{\text {th }}$ ASEE/IEEE Frontiers Education Conference. October 18-21, 2009, San Antonio, TX.

VALLIM, M. B. R.; HERDEN, A.; GALLO, R.; CARDOSO, L. R.; BITENCOURT, L. C. Incentivando Carreiras na Área Tecnológica Através da Robótica Educacional. . In: Congresso Brasileiro de Ensino de Engenharia, 37., 2009, Recife. Anais do XXXVII Congresso Brasileiro de Ensino de Engenharia, Recife, 2009. p. 01-10.

RECEBIDO EM: 20/09/2013.

APROVADO EM: 21/09/2015. 